\title{
O codesign para geração de valor e inovação no desenvolvimento de produtos de vestuário
}

Luciana da Silva Bertoso

Doutoranda, Universidade Federal do Paraná / lu.bertoso@gmail.com Orcid: 0000-0003-0573-0144 / lattes

Adriano Heemann

Doutor, Universidade Federal do Paraná / adriano.heemann@gmail.com Orcid: 0000-0002-7029-4505 / lattes

Enviado: 31/05/2019 // Aceito: 06/10/2020 


\title{
O codesign para geração de valor e inovação no desenvolvimento de produtos de vestuário
}

\begin{abstract}
RESUMO
O presente artigo aborda os processos de inovação em empresas de vestuário, com intuito de analisar como a colaboração entre os stakeholders podem contribuir para a geração de valor e inovação. Inicialmente, uma Revisão Bibliográfica delineia o quadro teórico sobre o qual se fundamenta o assunto e que é confirmado empiricamente por meio de um Estudo de Caso junto a uma empresa brasileira. Os resultados apresentados e discutidos revelam aspectos novos sobre os fatores causais da criação de valor e da inovação. O estudo conclui com a constatação de duas relações causais no desenvolvimento de produtos de vestuário: o processo criativo e colaborativo entre distintos stakeholders, neste estudo denominado de codesign, é fator que está para a geração de valor assim como a gestão de relacionamento está para a inovação.
\end{abstract}

Palavras-chave: setor de vestuário, codesign, inovação. 


\title{
The codesign for value creation and innovation in the development of clothing products
}

\begin{abstract}
This article approaches the innovation processes in clothing industry in order to analyse how collaboration among stakeholders may generate value and innovation. At first, a Bibliographic Review outlines the theoretical framework on which the subject is based and empirically proved through a Case Study held in a Brazilian company. The results presented and discussed herein disclose new aspects on facts which give rise to value and innovation. This study lead to the conclusion of two casual relationships in clothing product development: the creative and collaborative process between different stakeholders, in this study denominated codesign, is essential for value generation as relationship management is for innovation.
\end{abstract}

Keywords: clothing industry, codesign, innovation. 


\title{
El codesign para la creación de valor y la innovación en el desarrollo de prendas de vestir
}

\begin{abstract}
RESUMEN
En este artículo se analizan los procesos de innovación en las empresas de confección, con el fin de analizar cómo la colaboración entre los stakeholders puede contribuir a la generación de valor e innovación. Inicialmente, una Revisión Bibliográfica esboza el marco teórico en el que se basa la asignatura y que se confirma empíricamente a través de un Estudio de Caso con una empresa brasileña. Los resultados presentados y discutidos revelan nuevos aspectos sobre los factores causales de la creación de valor y la innovación. El estudio concluye con el hallazgo de dos relaciones causales en el desarrollo de productos de confección: el proceso creativo y colaborativo entre diferentes stakeholders, en este estudio denominado codeign, es un factor que es para la generación de valor así como la gestión de relaciones es para la innovación.
\end{abstract}

Palabras clave: sector confección, codiseño, innovación. 


\section{INTRODUÇÃO}

A cadeia produtiva têxtil e de confecção passa por transformações decorrentes principalmente do processo de globalização econômica, que ocasiona o deslocamento da fabricação devido a fatores como custo, acirrada concorrência, mudanças tecnológicas, novos sistemas de informação e mudanças nas estruturas dos mercados ( $R E C H$, 2006). Nesse sentido, valores intangíveis como o foco na experiência com o consumidor passam cada vez mais a ser considerados no desenvolvimento de produtos e serviços com o objetivo de produzir, vender, comunicar e distribuir (GOMEZ et al., 2012).

O capitalismo contemporâneo encontra-se em uma perspectiva pós-industrial, na qual o conhecimento não é apenas um input para produção de mercadorias. Ele é um meio pelo qual os stakeholders compartilham experiências e geram inovações (COCCO, 2010). Apesar do importante avanço nos estudos sobre inovação, os debates entre especialistas demonstram que as categorizações e descrições adotadas nos manuais para elaborar seus indicadores são incipientes ou restritas. Há muitos desafios relacionados ao aprendizado dos processos de inovação, pois eles se transformam constantemente.

Nesse contexto três temas centrais são considerados especialmente relevantes para compreensão e aplicação da inovação nas organizações: a aprendizagem, as formas de colaboração e as especificidades de uma área de ponta, dentro do setor mais dinâmico da economia, o de serviços (ISSBERNER, 2010).

No âmbito do presente artigo, parte-se da ótica de que os projetos orientados para a colaboração (a experiência e o aprendizado) podem ser oportunidades de geração de valor e 
de inovação no desenvolvimento criativo de sistemas, produtos e serviços. Esse arranjo particular de desenvolvimento criativo é, no presente artigo, denominado codesign, que pode ser considerado tanto uma estratégia como um processo de diferenciação da organização no mercado (SEBRAE, 2014). Em um sentido mais profundo, o codesign aponta para a possibilidade da criação de uma combinação única de valor, um caminho de inovação.

É por meio do trabalho em equipe, de tal modo engajado e compartilhado, que podem ser estabelecidas redes de colaboração. Esse tipo de arranjo propicia uma nova lógica de consumo pautada na criação e no compartilhamento de conhecimento considerando a produção, a distribuição e o financiamento de bens tangíveis e intangíveis.

Considerando essa perspectiva, as indústrias brasileiras de vestuário passaram a direcionar estratégias para a colaboração no desenvolvimento de produtos (SEBRAE, 2014). Assim, é possível supor que o campo geral do design poderá assumir que a colaboração entre pessoas torne-se parte da estratégia de inovação no setor de vestuário.

Entretanto, embora o setor de vestuário brasileiro tenha se beneficiado com as estratégias de inovação adotadas nos últimos anos, uma Revisão Bibliográfica Sistemática (RBS) realizada nas bases de dados Google Acadêmico, Portal de periódicos da CAPES e Banco de teses e dissertações da CAPES, entre os anos de 2005 e 2016, apontou para uma importante carência de estudos científicos que descrevam o papel e o potencial do codesign na geração de valor e na promoção de inovações no setor de vestuário.

A RBS levantou 22 publicações relevantes. Contudo, destas publicações, apenas duas correlacionam diretamente 0 codesign, a inovação e o setor de vestuário. A primeira referência é um boletim de tendências do SEBRAE (2014) com 
recomendações para utilizar o codesign no pequeno negócio de moda. Essa estratégia significa envolver clientes, funcionários, fornecedores e parceiros de negócios no processo de desenvolvimento de produtos visando o aumento de vendas (SEBRAE, 2014).

A segunda publicação extraída da RBS é um livro de Ramaswamy e Gouillart (2010) sobre 26 estudos de casos em empresas, dos quais 2 apontam a aplicação do codesign no setor de vestuário na Wacoal que produz lingeries no Japão (atualmente exporta para vários países) e desde 2001 utiliza esse processo e no Camiseteria, empresa brasileira escolhida para esse estudo de caso.

Além disso há outros casos de codesign no setor de vestuário: o coletivo Verde, uma startup com plataforma de cocriação de produtos sustentáveis, onde as pessoas são convidadas a participar do desenvolvimento de produtos; a Saint Society, uma rede social que e as pessoas criam painéis com imagens que servem de inspiração para a criação de coleções da marca; e a americana Threadless, que utiliza o crowdsourcing para cocriar estampas de camisetas com os usuários (RAMASWAMY; GUILLART, 2010; SEBRAE, 2014).

Essa lacuna, aqui evidenciada, delimita o problema da presente investigação. A partir desses esclarecimentos introdutórios, são apresentados a seguir o delineamento metodológico, os resultados alcançados e sua discussão. A conclusão apresenta visa contribuir para o esclarecimento desse complexo tema e para a abertura de oportunidades teóricas o campo da Moda e seus desdobramentos.

\section{Método}

Os conceitos oriundos do procedimento de Revisão Bibliográfica servem de fundamento teórico para um Estudo 
de Caso junto a empresa de vestuário Camiseteria, fundada em 2005 na cidade do Rio de Janeiro (CAMISETERIA, 2019). Os critérios para seleção deste caso empírico são a consolidação da empresa no mercado e a adoção pela empresa do codesign como processo de desenvolvimento. A unidade primária de análise é o conjunto de atores diretamente envolvidos com o processo de codesign (funcionários, sócios, consumidores/usuários). As técnicas utilizadas para coleta de dados são a pesquisa documental em conteúdo da internet, a observação direta e participante e as entrevistas semiestruturadas. Para análise dos dados é adotada o procedimento de análise de conteúdo nas entrevistas, na internet e durante as observações, delineando categoriais de análise embasadas pelo quadro teórico.

\section{Resultados}

\subsection{O intangível na criação e comercialização de vestuário}

Existem duas principais dimensões do processo de acumulação da indústria têxtil: os ativos materiais, tangíveis (novos maquinários, novos tecidos) e os ativos imateriais, intangíveis, que se mostram cada vez mais essenciais, tais como o design, marketing, marcas, logística e assistência aos fornecedores. Empresas que comandam este setor concentram-se em desenvolver valores intangíveis e deslocam sua produção para locais onde a mão de obra é mais barata, por meio da subcontratação (LUPATINI, 2004).

Desta forma, quando há valorização do aspecto intangível, este passa a influenciar o funcionamento da cadeia com as funções de marketing, atividades financeiras, design e canais de distribuição (RECH, 2006). Essa valorização se reflete nos 
produtos de vestuário que são segmentados de acordo com o público-alvo da empresa. Nesse cenário ocorre também uma segmentação em relação às estratégias competitivas, processos produtivos e padrões de concorrência.

A criação de produtos de vestuário, realizado pelas empresas de confecção, é processo importante para a obtenção de produtos/serviços que sejam atrativos ao consumo e, consequentemente, competitivos no mercado, e que sejam soluções eficazes para os usuários/consumidores (MONTEMEZZO, 2003). Em consideração a isso, a metodologia projetual se transformou ao longo dos anos integrando valores emocionais relacionados aos aspectos psicossociais dos usuários integrados à dinâmica de seu contexto.

Outro fator considerado por essas empresas é a busca por vantagem competitiva, que depende de fatores internos e externos à empresa, à esfera industrial e à situação econômica do setor produtivo (RECH, 2006). Dentre os fatores internos da empresa destacam-se a produtividade, a inovação e os recursos humanos.

A vantagem competitiva advém de estratégias organizacionais que possibilitam um arranjo competitivo favorável para estabelecer uma posição lucrativa e sustentável. A concorrência nesse setor está baseada na diferenciação de preço e qualidade-criatividade, além da incorporação de elementos como estilo e design além da capacidade de gerenciar mudanças (RECH, 2006). Perante este panorama, empresários e pesquisadores formulam novas estratégias sobre para a cadeia produtiva têxtil, tais como a reorientação de processos quanto às atuais condições sociais, ecológicas e ações em colaboração.

No presente estudo, parte-se da premissa de que essas estratégias podem ser operacionalizadas por meio de ações 
compartilhadas de design orientadas a geração de valor e promoção da inovação no setor de vestuário.

\subsection{A colaboração para geração de valor e inovação}

O processo de inovação no setor de vestuário é complexo. Um dos desafios para se inovar é dar atenção às demandas dos consumidores, que se tornam cada vez mais exigentes em relação aos aspectos ambientais, segurança, ergonomia e preço. Em contrapartida, as empresas lidam com limitações no orçamento, tecnologia, registro de patente, incertezas e riscos ao investir em inovação. Como consequência, torna-se cada vez mais difícil oferecer produtos competitivos no mercado (COSTA, 2011).

Perante os desafios da inovação a metodologia projetual auxilia o desenvolvimento de soluções que possam se adequar às necessidades e limitações de uma organização. As equipes de projeto atualmente executam o trabalho em parceria, com maior flexibilidade, pois o processo de desenvolvimento de produtos de vestuário também é complexo por demandar a integração de diversos setores e empresas.

As etapas projetuais para o desenvolvimento de vestuário englobam desde o planejamento com as definições do escopo do projeto, especificações, delimitação conceitual, geração de alternativas, avaliação e elaboração até a realização da coleção e distribuição dos produtos (MONTEMEZZO, 2003).

O presente estudo adota como referência as três abordagens de design de Moda propostas por Rech (2002), Montemezzo (2003) e Treptow (2013) descritas no Quadro 1. 
Quadro 1. Etapas do desenvolvimento de produtos de Moda.

\begin{tabular}{|c|c|c|}
\hline MONTEMEZO (2003) & RECH (2002) & TREPTOW (2013) \\
\hline Planejamento & Geração do conceito & Planejamento \\
\hline Especificação do projeto & \multirow{2}{*}{ Triagem } & \multirow{3}{*}{ Design } \\
\hline Delimitação conceitual & & \\
\hline Geração de alternativas & Projeto preliminar & \\
\hline Avaliação e elaboração & $\begin{array}{l}\text { Avaliação, melhoramento e } \\
\text { Prototipagem }\end{array}$ & \multirow[t]{2}{*}{ Desenvolvimento } \\
\hline Realização & Projeto final & \\
\hline
\end{tabular}

Fonte: os autores

A primeira etapa de planejamento (MONTEMEZZO, 2003; TREPTOW, 2013) ou de geração do conceito (RECH, 2002) consiste na coleta e análise de informações do mercado e do histórico de produtos da empresa, além da definição do cronograma do projeto. As etapas de especificação do projeto e delimitação conceitual (MONTEMEZZO, 2003) ou de triagem (RECH, 2002) ou de design (TREPTOW, 2013) englobam a delimitação do problema de design, o direcionamento mercadológico do projeto e as metas técnicas, funcionais e estéticas, além do mix de produtos a ser devolvido.

Já a etapa de geração de alternativas (MONTEMEZZO, 2003) ou projeto preliminar ( $\mathrm{RECH}, 2002)$ é caracterizado pela geração e esboço de ideias para a coleção. A fase de avaliação, elaboração, melhoramento e prototipagem (MONTEMEZZO, 2003; RECH，2002) correspondem às atividades de seleção das alternativas coerentes com o projeto, modelagem para elaboração dos protótipos e desenhos técnicos. Por fim, a realização (MONTEMEZZO, 2003) ou projeto final ( $\mathrm{RECH}, 2002)$ ou desenvolvimento (TREPTOW, 2013) concretiza o projeto de vestuário com a elaboração das fichas técnicas, produção do mostruário, desfiles, embalagens e material para divulgação.

Diante dos distintos modelos procedurais que podem ser adotados e da complexidade inerente ao processo de 
fabricação de vestuário, a cooperação e a gestão do relacionamento constituem fatores relevantes para eficácia do projeto. O envolvimento da equipe de desenvolvimento de produto com o marketing e vendas (assim como outros setores da empresa) promove a integração dos stakeholders, o que pode aumentar chances de sucesso de um produto (BAXTER, 2008).

Além disso, o desenvolvimento de produtos envolve distintos interesses e habilidades, pois ele "é necessariamente uma solução de compromissos" (BAXTER, 2008, p.2). Por isso, é preciso chegar a um consenso entre os interesses divergentes de cada pessoa e/ou empresa envolvida para a execução de um projeto integrado (MONTEMEZZO, 2003).

Nesse contexto, a globalização e o mundo em rede trazem novas realidades para a inovação e, apesar do grande avanço dos estudos, os debates entre especialistas evidenciam que as categorizações e descrições adotadas nos manuais técnicos as vezes se mostram incipientes ou restritos. Além disso, há muitas dificuldades em aprender sobre os processos de inovação, pois eles se transformam constantemente (CGEE, 2010).

Issberner (2010) sugere que as novas formas de inovação são baseadas em interações e colaboração não lineares e ocorrem entre atores sociais dispersos na rede. As transformações nos processos de inovação trazem a necessidade de elaboração de novos indicadores que considerem a análises sobre o papel do aprendizado na inovação, que é fator-chave do processo inovador.

As análises sobre as interações e a colaboração vêm ganhando importância ante o esquema tradicional linear de se conceber inovações. As redes de inovação baseadas na internet dão novo significado às relações entre ciência, tecnologia e conhecimentos de outras naturezas e são uma 
forma de diluir os altos custos do processo de aprendizagem de saberes especializados (ISSBERNER, 2010).

Mas o uso das redes no processo de inovação também traz alguns questionamentos sobre a escolha das organizações com as quais se deseja interagir e sobre os objetivos dos stakeholders, que às vezes podem ser conflitantes. Nas redes há uma transformação contínua de conhecimentos, ideias e sentidos, que geram conhecimento e aprendizado. Ou seja, o lócus da inovação parece não se concentrar na empresa, mas nas interações que a inovação aparenta demandar.

O conhecimento nesse processo sistêmico de inovação torna-se um output e não apenas um input para geração de valor. Ele não se restringe a um bem físico, mas ao cenário construído, ou seja, o significado criado e que se propaga nas redes de interação. Ou seja, aspectos intangíveis influenciam a competitividade. O conhecimento gerado, explorado, aplicado e comercializado pode contribuir para o sucesso de novos produtos (RECH, 2006).

Essa forma de conceber produtos baseada na colaboração e disseminação do conhecimento apresenta um desafio novo em relação a forma tradicional de se realizar as atividades de inovação confidencial e sigilosa. Ou seja, há demanda por estudos aprofundados que esclareçam as formas de inovação por meio da colaboração entre stakeholders.

Para Cocco (2010), a inovação não estaria na apropriação de um conhecimento, mas na capacidade de transformar e recriar significados. As novas formas de inovação baseadas em interações e colaboração não são lineares: ocorrem entre atores sociais dispersos nas redes (ISSBERNER, 2010). 


\subsection{O codesign como oportunidade de inovação}

O conceito de colaboração aparece com mais força no design quando leva em consideração o potencial humano (FONTANA; HEEMANN; GITIRANA, 2012). De acordo com Kleinsmann (2006), o design colaborativo é um processo no qual atores de diferentes áreas compartilham seus conhecimentos tanto sobre o processo de design como sobre o conteúdo do design. Eles fazem isso com o objetivo de criar entendimento compartilhado em ambos os aspectos, para serem aptos a integrar e explorar seus conhecimentos e para atingir o maior objetivo em comum: o novo produto a ser projetado.

Fontana, Heemann e Gitirana (2012) acrescentam que esses atores sociais podem estar separados fisicamente, ou não, realizando interações e compartilhando conhecimentos em um processo de design, através de uma grande variedade de fontes de informação, que exigem certo grau de coordenação, o estabelecimento de uma relação de confiança e a dedicação de cada parte para geração e integração de conhecimentos.

Os stakeholders envolvidos no projeto de design se comunicam oralmente e através de textos compartilhando e criado conhecimentos sobre o projeto, além disso, os desenhos e protótipos têm um papel importante na comunicação do design (KLEINSMANN, 2006).

Já, para Faud-Luke (2009), o codesign é um termo amplo usado para indicar "projetando com" outros, engloba abordagens correlatas como o design participativo, metadesign, design social e outras abordagens do design que estimulam a participação. Para o autor, o codesign oferece a oportunidade de definição coletiva do problema, aumentando as chances de eficácia de um novo produto. 
A prática da criatividade coletiva no design ficou mais marcante há cerca de 40 anos, com a promoção do design participativo, que recentemente passou a ser englobado pelo conceito mais amplo de cocriação ou codesign. O design participativo foi fortemente divulgado no norte da Europa (Noruega, Dinamarca e Suécia) por meio de projetos coletivos para mudança do local de trabalho. A tarefa parece ter sido desenvolvida colaborativamente entre designers e os próprios funcionários do local, o que gerou nos trabalhadores a experiência de modificar aquela situação (SANDERS; STAPPERS, 2008).

Sanders e Stappers (2008) discutem os termos codesign e cocriação e sugerem que ambos não podem ser considerados sinônimos. Conforme os autores, a cocriação é entendida como o processo ou resultado de uma criatividade coletiva genérica, compartilhada entre pessoas com intuito de desenvolver uma solução para um problema de qualquer área. Já, codesign, estaria associado a aplicação da cocriação ao campo do design. Ou seja, os autores entendem o codesign como uma criatividade coletiva específica do design.

As práticas de design se transformam e não se restringem a projetar produtos para usuários, mas também experiências para pessoas que, cada vez mais, estão conectadas e recebendo informação. Consequentemente, os estudos mais recentes de design precisam considerar 0 aspecto informacional das novas ênfases inerentes ao campo, como a do design interativo, do design de serviços e do design de transformação. Essas ênfases constroem sobre o campo teórico do design tradicional novas competências para resolver novos problemas sociais e econômicos.

Sanders e Stappers (2008) ainda sugerem que o papel dos stakeholders no processo de design parecem estar mudando junto com a transição do design centrado no usuário para o 
codesign. No codesign, o usuário passa a ser visto como um "expert" sobre sua própria experiência e desempenha um papel essencial no desenvolvimento de conhecimento, geração de ideia e desenvolvimento de conceito. O pesquisador apoia o usuário oferecendo ferramentas. 0 designer e o pesquisador (que podem ser a mesma pessoa) colaboram, pois o designer é importante para o desenvolvimento das ferramentas e desempenha o papel fundamental de dar forma às ideias.

Com isto, o codesign parece estar no núcleo de um processo de design mais democrático e aberto e encontra expressão tanto nos negócios quanto em setores não lucrativos. O codesign pode gerar novas formas de interagir e novos valores, mas demanda um novo conjunto de habilidades (FAUD-LUKE, 2009).

\subsection{Aplicações do codesign no desenvolvimento de produtos de vestuário}

A Camiseteria, empresa de vestuário analisada no Estudo de Caso, realiza concursos de crowdsourcing como forma de engajar pessoas no processo de desenvolvimento de produtos em um e-commerce. Os atores que participam desse engajamento e que configuram dentre os entrevistados são: Sócia A - Financeiro; Sócio B - Marketing; Sócio C - Design; Usuário da Comunidade - Designer, com 55 estampas aprovadas, que há 7 anos participa da comunidade. Os resultados das entrevistas são apresentados em categorias de síntese no Quadro 2. 
Quadro 2. Comparação dos resultados das entrevistas.

\begin{tabular}{|c|c|c|c|c|}
\hline Stakeholders & Inovação & $\begin{array}{c}\text { Colaboraçãol } \\
\text { codesign }\end{array}$ & $\begin{array}{c}\text { Como ocorre } \\
\text { o codesign }\end{array}$ & $\begin{array}{c}\text { Relação das ações de } \\
\text { codesign com a inovação }\end{array}$ \\
\hline $\begin{array}{l}\text { SÓCIAA } \\
\text { Financeiro }\end{array}$ & $\begin{array}{l}\text { O nosso diferencial no } \\
\text { mercado é atendimento e } \\
\text { o nosso produto em si. }\end{array}$ & $\begin{array}{l}\text { E a interaçãa } \\
\text { com o } \\
\text { consumidor. }\end{array}$ & $\begin{array}{l}\text { Recebimento } \\
\text { da estampa, } \\
\text { pré-análise, } \\
\text { votação, } \\
\text { segunda } \\
\text { análise, } \\
\text { escolha, } \\
\text { checagem de } \\
\text { qualidade e } \\
\text { venda. }\end{array}$ & $\begin{array}{l}\text { O codesign proporciona a } \\
\text { interação do usuário e isso } \\
\text { gera um diferencial, além } \\
\text { da qualidade das } \\
\text { estampas. }\end{array}$ \\
\hline $\begin{array}{l}\text { SOCIO B } \\
\text { Marketing }\end{array}$ & $\begin{array}{l}\text { E o conjunto da } \\
\text { reciclagem de ideias, que } \\
\text { resultou na nossa } \\
\text { comunidade. }\end{array}$ & $\begin{array}{l}\text { E a utilização de } \\
\text { diversas ideias, } \\
\text { imagens e } \\
\text { qualidades para } \\
\text { agregar valor no } \\
\text { negócio. } \\
\end{array}$ & $\begin{array}{l}\text { Envio da } \\
\text { estampa, } \\
\text { curadoria, } \\
\text { votaçãoe } \\
\text { lançamento. }\end{array}$ & $\begin{array}{l}\text { A colaboração e o codesign } \\
\text { estão diretamente } \\
\text { relacionados à inovação, } \\
\text { comprovada pela } \\
\text { permanência da empresa } \\
\text { no mercado. }\end{array}$ \\
\hline $\begin{array}{l}\text { SóclO C } \\
\text { Design }\end{array}$ & $\begin{array}{l}\text { É o estabelecimento de } \\
\text { laços, não somos apenas } \\
\text { empresa que vende um } \\
\text { produto, conseguimos } \\
\text { gerar aprendizado } \\
\text { compartilhado. }\end{array}$ & $\begin{array}{l}\text { E a ajuda do } \\
\text { público, } \\
\text { buscando um } \\
\text { modelo } \\
\text { democrático. }\end{array}$ & $\begin{array}{l}\text { Discussão } \\
\text { entre os } \\
\text { designes, } \\
\text { criação, pré- } \\
\text { divulgação e } \\
\text { votação. } \\
\end{array}$ & $\begin{array}{l}\text { A participação do público } \\
\text { faz com que nós inovemos } \\
\text { com om um produto mais } \\
\text { personalizado do que dos } \\
\text { nossos concorrentes. }\end{array}$ \\
\hline $\begin{array}{l}\text { USUÁRIO } \\
\text { Designer }\end{array}$ & $\begin{array}{l}\text { A ideia do modelo de } \\
\text { negócio colaborativo e } \\
\text { deixar o designer à } \\
\text { vontade para criar, não é } \\
\text { uma coisa rígida como } \\
\text { em uma empresa } \\
\text { tradicional. }\end{array}$ & $\begin{array}{l}\text { E um modelo } \\
\text { colaborativo que } \\
\text { dá a liberdade } \\
\text { de criação para } \\
\text { os designers. }\end{array}$ & $\begin{array}{l}\text { Concurso, } \\
\text { envio da } \\
\text { estampa, } \\
\text { votaçãa, } \\
\text { escolha, teste } \\
\text { produção. }\end{array}$ & $\begin{array}{l}\text { A inovação está no modelo } \\
\text { colaborativo com o auxílio } \\
\text { aos novos designers que } \\
\text { estão começando a } \\
\text { trabalhar com estamparia e } \\
\text { a valorização do nosso } \\
\text { trabalho financeiramente e } \\
\text { na criatividade. }\end{array}$ \\
\hline
\end{tabular}

Fonte: BERTOSO (2017).

Após a análise preliminar das entrevistas, foram geradas subcategorias de análise. Entre as mais citadas é possível destacar a palavra "designer" (citada 68 vezes). Isso sugere que o designer é um ator importante na comunicação verbal da empresa. A análise aponta que ele é quem desenvolve as estampas e coordena o processo. Foram citadas as subcategorias "comunidade" (citada 38 vezes), que é a plataforma de engajamento no processo de codesign; "concursos" (citada 17 vezes), que é o meio pelo qual ocorre o codesign com stakeholders externos à empresa; e "design" (citada 13 vezes), que é o elemento central do processo criativo que agrega valor no desenvolvimento de produto.

Os resultados da análise de conteúdo da internet, por sua vez, estão sintetizados no Quadro 3. 
Quadro 3. Resultados da análise de conteúdo na internet e observações.

\begin{tabular}{|l|l|}
\hline Categoria de análise & Resultados \\
\hline Plataforma de engajamento & $\begin{array}{l}\text { O engajamento dos usuários/consumidores é feito } \\
\text { em uma plataforma virtual, o site da empresa, é } \\
\text { considerado uma comunidade online. }\end{array}$ \\
\hline Participação dos usuários & $\begin{array}{l}\text { Os usuários podem participar da comunidade nos } \\
\text { concursos de estampas, na votação das } \\
\text { estampas, nas redes sociais, programa de } \\
\text { afiliados (divulgação em site pessoal do designer } \\
\text { do Camiseteria) e troca de pontos (divulgação do } \\
\text { link da camiseta em site pessoal do designer, } \\
\text { acumula pontos quando outros usuários utilizam o } \\
\text { link para comprar a peça). }\end{array}$ \\
\hline Compartilhamento de conhecimento & $\begin{array}{l}\text { O conhecimento é compartilhado no BlogBoxe na } \\
\text { comunidade do Facebook, onde os designers } \\
\text { compartilham as suas artes e recebem críticas e } \\
\text { dicas de outros usuários, além de compartilharem } \\
\text { técnicas e outras questões de interesse sobre } \\
\text { estampas. }\end{array}$ \\
\hline Processo de cocriação & $\begin{array}{l}\text { O codesign ocorre nos concursos de estampas } \\
\text { Camiseteria. }\end{array}$ \\
\hline
\end{tabular}

Fonte: BERTOSO (2017).

As estampas são criadas por diversos stakeholders que as enviam para votação comunitária. Além disso, podem ser feitos comentários sobre as estampas estimulando o aprendizado e feedback. As estampas mais pontuadas são escolhidas e seus criadores ganham participação nos lucros das vendas.

Por meio do Estudo de Caso foi possível constatar que os produtos desenvolvidos com os usuários/consumidores constituem soluções factíveis para eles. Os aspectos psicossociais integrados à dinâmica do contexto em que se inserem os usuários/consumidores são contemplados no produto e estabelecem uma relação emocional com eles (MONTEMEZZO, 2003). 
Deste modo, as observações do estudo foram contrastadas com as fases gerais de desenvolvimento de produtos de moda anteriormente mencionadas no presente artigo, propostas por Rech (2002), Montemezo (2003) e Treptow (2013). Conforme esses modelos, na etapa inicial de planejamento, há a colaboração dos atores internos e externos às empresas para concepção de como ocorrerá a cocriação. A empresa aciona o marketing, o financeiro e o design para o planejamento dos concursos. Nesta etapa ocorre também o direcionamento mercadológico, a geração do conceito e especificações do projeto. O direcionamento é passado para os participantes da comunidade por meio do briefing do concurso.

Em conformidade com o modelo preconizado na teoria, após o planejamento, a empresa segue com a atividade de geração de alternativas, que é realizada pelos participantes que elaboram as estampas e que as enviam para críticas e pré-aprovação da comunidade. A terceira etapa é de avaliação, em que a empresa faz uma triagem das estampas enviadas para o concurso e, em seguida, submete as estampas candidatas a votação da comunidade. Na fase de prototipagem, a empresa testa as estampas vencedoras do concurso. Finalmente, o que corresponde a fase de realização, as estampas vencedoras são produzidas. Após a confecção das camisetas, as mesmas são disponibilizadas para venda pelo e-commerce e os autores das estampas recebem uma porcentagem do faturamento além de possíveis premiações em concursos.

Em relação as etapas de codesign mencionadas por FaudLuke (2009), na empresa observada o briefing é delineado coletivamente pelos stakeholders internos. Já, na etapa seguinte, são desenvolvidas as ideias que não são materializadas em protótipos, o que contraria o modelo teórico do autor. Somente após as propostas serem 
selecionadas pela votação é que a empresa executa a prototipação das estampas eleitas que, posteriormente são finalmente produzidas e comercializadas.

O Quadro 4 sintetiza os processos de codesign da empresa Camiseteria e as classifica segundo as etapas teóricas de Rech (2002), Montemezzo (2003) e Treptow (2013), bem como de Faud-Luke (2009), destacando a ocorrência da colaboração com os usuários/consumidores no desenvolvimento de produto.

Quadro 4. Etapas do codesign no processo de desenvolvimento de produto de vestuário

\begin{tabular}{|c|c|c|}
\hline $\begin{array}{l}\text { Etapas do processo de } \\
\text { desenvolvimento } \\
\text { produto de vestuário com } \\
\text { base em Montemezzo } \\
\text { (2013), Rech (2002) e } \\
\text { Treptow (2013) }\end{array}$ & $\begin{array}{l}\text { Etapas do codesign com } \\
\text { base em Faud-Luke (2009) }\end{array}$ & $\begin{array}{l}\text { Estudo de caso } \\
\text { Confecção de camisetas }\end{array}$ \\
\hline Planejamento & $\begin{array}{ll}\text { Definição coletiva } & \text { do } \\
\text { problema e do briefing } & \end{array}$ & $\begin{array}{l}\text { Concepção dos concursos, } \\
\text { envolvimento do marketing, } \\
\text { financeiro e design. Análise } \\
\text { de mercado e público-alvo na } \\
\text { comunidade e redes sociais: } \\
\text { pesquisa das tendências de } \\
\text { estampas. }\end{array}$ \\
\hline Geração de alternativas & $\begin{array}{l}\text { Definição de propostas, e } \\
\text { prototipação }\end{array}$ & $\begin{array}{l}\text { Designers elaboram } \\
\text { estampas e enviam para } \\
\text { críticas e pré-aprovação da } \\
\text { comunidade. }\end{array}$ \\
\hline Avaliação & $\begin{array}{l}\text { Seleção dos protótipos ou } \\
\text { propostas }\end{array}$ & $\begin{array}{l}\text { Tiragem das estampas } \\
\text { enviadas feita pelos } \\
\text { stakeholders internos da } \\
\text { empresa, após é realizada a } \\
\text { votação na comunidade. }\end{array}$ \\
\hline Prototipagem & & $\begin{array}{l}\text { Teste das estampas } \\
\text { vencedoras do concurso }\end{array}$ \\
\hline Realização/Desenvolvimento & $\begin{array}{l}\text { Especificações, } \\
\text { detalhamento } \\
\text { implementação }\end{array}$ & $\begin{array}{l}\text { Confecção das camisetas } \\
\text { conforme a demanda de } \\
\text { vendas. }\end{array}$ \\
\hline
\end{tabular}

Fonte: os autores. 
Cabe observar que a integração dos atores no desenvolvimento de produto contribui para a melhoria dos resultados, gerando produtos que são analisados antes do lançamento pela comunidade, o que facilita a absorção das propostas no mercado.

Em relação à integração do design, a empresa conta com designers que são atores internos e integram outros designers no processo de codesign. Os designers atuam em colaboração com os encarregados pelo marketing, coordenando os concursos e gerenciando as estampas (banco de dados, temas, autores, entre outros).

Em relação aos desafios de implementação do codesign, o estudo aponta que o estabelecimento de parcerias e a sua longevidade constituem um desafio. Anualmente milhares de usuários ingressam na comunidade da Camiseteria, porém poucos permanecem nela por mais de um ano. Por um lado, a empresa também atua como uma "escola" para novos designers e, nesse sentido, a flutuação de usuários pode ser um aspecto prejudicial. Contudo, a empresa prioriza a gestão de relacionamento com usuários e designers mais experientes.

Portanto, o codesign observado empiricamente por meio do Estudo de Caso, situa a experiência humana no centro do processo. A interação ocorre de maneira que os partícipes (atores internos e externos) possam alcançar os resultados desejados e o fortalecimento da interação. O valor que o usuário vincula ao produto construído a partir da sua experiência pessoal.

\section{Considerações finais}

A Moda é campo de conhecimento indissociável da sociedade contemporânea. Nesse contexto, a inovação e a 
geração de valor, embora constituam temas complexos e desafiadores, têm sido reconhecidos pelas empresas de vestuário como fatores importantes para a diferenciação competitiva no mercado.

Como é fundamentado nos modelos teóricos resgatados pela Revisão Bibliográfica e observado empiricamente pelo Estudo de Caso junto a empresa Camiseteria, o presente estudo confirma a premissa de que o codesign pode constituir subsídio tanto para a geração de valor como para a promoção da inovação.

Contudo, o estudo também revela que, no que concerne a inovação, a prioridade da empresa está na integração dos stakeholders. Ou seja, enquanto o codesign é o fator causal mais diretamente relacionado a geração de valor, a gestão de relacionamento é o fator causal mais diretamente relacionado a inovação.

A partir desta constatação, embora esses fatores também se influenciem mutuamente em uma complexa relação de causas e efeitos, um esclarecimento adicional a esse respeito fugiria do escopo da presente investigação constituindo, portanto, aspecto que poderia ser melhor compreendido por pesquisas futuras no campo da Moda.

\section{Agradecimentos}

Ao CNPq e a CAPES pelo apoio na forma de bolsa de estudos.

\section{Referências}

BAXTER, Mike. Projeto de Produto: guia prático para o design de novos produtos. $2^{\mathrm{a}}$ ed. São Paulo: Blucher, 2000.

BERTOSO, Luciana da Silva. A cocriação como estratégia de inovação no setor de vestuário. 2017. 140 fls. (Dissertação de 
Mestrado) - Programa de Pós-Graduação em Design - Universidade Federal do Paraná, Curitiba- PR, 2017.

CAMISETERIA. Disponível em <https://www.camiseteria.com/default.aspx> Acesso em 03/03/2019.

CGEE - CENTRO DE GESTÃO E ESTUDOS ESTRATÉGICOS. Bases conceituais em pesquisa, desenvolvimento $e$ inovação: Implicações para políticas no Brasil. Brasília: CGEE, 2010.

COCCO, Giuseppe. Indicadores de inovação e capitalismo cognitivo. In: CENTRO DE GESTÃO E ESTUDOS ESTRATÉGICOS (CGEE). Bases conceituais em pesquisa, desenvolvimento e inovação: Implicações para políticas no Brasil. Brasília: CGEE, 2010. p. 33-68.

COSTA Maria Izabel. Políticas de design para o fomento da inovação na cadeia de valor Têxtil/Confecção de moda de Santa Catarina. 270 f. Tese (Doutorado em Design) Departamento de Artes \& Design, Pontifícia Universidade Católica, Rio de Janeiro, 2011.

FUAD-LUKE, Alastair. Design activism: beautiful strangeness for a sustainable world. USA: Earthscan, 2009.

FONTANA, Isabela. M.; HEEMANN, Adriano; FERREIRA, Marcelo. G. G. Design Colaborativo: Fatores Críticos para o Sucesso do Codesign. In: Congresso Sul Americano de Design de Interação, 4., 2012, São Paulo. Anais... São Paulo: $4^{\circ}$ Congresso Sul Americano de Design de Interação, 2012. p. 371-382.

GOMEZ, L. S. R. et al. O DNA da marca de moda: O processo. In: CANTISTA, Isabel. (Org.). A moda num mundo global. Portugal: Vida Econômica, 2012. p. 134- 56.

ISSBERNER, Liz-Rejane. Em direção a uma nova abordagem da inovação: coordenadas para o debate. In: CENTRO DE GESTÃO E ESTUDOS ESTRATÉGICOS (CGEE). Bases conceituais em pesquisa, desenvolvimento e inovação: Implicações para políticas no Brasil. Brasília: CGEE, 2010. p. 11-32.

KLEISMAN, M. Understanding collaborative design. 309 f. Tese (Doutorado) - Faculty of Industrial Design Engineering, Delft University of Technology, Holanda, 2006.

LUPATINI, M. P. As Transformações produtivas na Indústria têxtil-vestuário e seus impactos sobre a distribuição territorial da produção e a divisão do trabalho industrial. 168 f. Dissertação (Mestrado em Política Científica e Tecnologia) Instituto de Geociências, Universidade Estadual de Campinas, Campinas - SP, 2004.

MONTEMEZZO, Maria Celeste de Fátima Sanches. Diretrizes metodológicas para o projeto de produtos de moda no âmbito acadêmico. 97 f. Dissertação (Mestrado em Design) - Faculdade de Arquitetura, Artes e Comunicação, Universidade Estadual Paulista, Bauru-SP. 2003.

RAMASWAMY, Venkat; GOUILLART, Francis. A empresa cocriativa - Por Que Envolver Stakeholders No Processo de Criação de Valor Gera Mais Benefícios Para Todos. Rio de Janeiro: Elsevier, 2010 
RECH, Sandra Regina. Cadeia produtiva da moda: um modelo conceitual de análise da competitividade no elo confecção. 301 f. Tese (Doutorado em Engenharia de Produção) - Programa de Pós-Graduação em Engenharia de Produção, Universidade Federal de Santa Catarina, Florianópolis-SC, 2006.

RECH, Sandra Regina. Moda: por um fio de qualidade. Florianópolis: UDESC, 2002.

SANDERS, Elizabeth B.N.; STAPPERS, Pieter J. Co-creation and the new landscapes of design. International Journal of CoCreation in Design and the Arts. v. 2, n. 1, p. 5-18, 2008.

SEBRAE. Cocriação: a união de ideias para inovar. SEBRAE Vestuário Boletim de tendências, mai. 2014. Disponível em $<$ https://atendimento.sebrae-

sc.com.br/webroot/projetos/portal_sebraesc/downloads/mercado/ 2014/boletins/boletim-maio-2014-vestuario.pdf > .

TREPTOW, Doris. Inventando moda: planejamento de coleção. 3.ed. Brusque: Do Autor, 2013. 